DOI: 10.12731/2658-6649-2021-13-3-261-275

УДК 582.572.8(470.47)

\title{
СТРУКТУРА МОРФОЛОГИЧЕСКОЙ ИЗМЕНЧИВОСТИ И ВИТАЛИТЕТНАЯ СТРУКТУРА ЦЕНОПОПУЛЯЦИЙ TULIPA GESNERIANA L. НА ЕРГЕНИНСКОЙ ВОЗВЫШЕННОСТИ
}

\author{
Н.Ц. Лиджиева, А.С. Очирова, \\ Ж.В. Овадыкова, С.В. Убушаева
}

Обоснование. Изучение жизненности индивидуумов и виталитетной структуры популящий является одним из актуальных подходов в оценке состояния редких видов растений, к которым относится объект исследования.

Цель. Определение структуры морфологической изменчивости и виталитетной структуры ценопопулящий Tulipa gesneriana L. на Ергенинской возвышенности.

Материалы и методы. Исследования проводили в течение двух вегетаиионных сезонов в трех ценопопуляциях из разных растительных сообществ. Уровень изменчивости 12 морфологических признаков растений оценивали по С.А. Мамаеву. В структуре изменчивости выделяли группы системных индикаторов. Для оченки пластичности признака использовали индекс фитоценотической пластичности, виталитетного спектра популяций-методику Ю.А. Злобина, виталитетной структуры популяции - индекс виталитета, виталитетного типа - критерий $Q$, степени процветания или депрессивности цеенопопуляций - индекс IQ.

Результаты. Большинство изученных признаков растений T. gesneriana в первый год исследования имели большие значения, чем в следующем году, варьируя при этом преимущественно среднем и повышенном уровне. В следующем году уровень варьирования признаков возрос.

Структуру изменчивости морфологических признаков $T$. gesneriana в первый год исследования слагали группы эколого-биологических и биологических системных индикаторов, в следующем году наряду с данными двумя группами появилась группа экологических системных индикаторов. Оченка жизненности цеенопопуляций T. gesneriana выявила, что они относятся $к$ типу «проиветающие». Степень процветания иченопопуляциий колебалась по годам. 
Заключение. Таким образом, ценопопуляции T. gesneriana относились $к$ виталитетному типу «проиветающие». Во второй год исследования в иенопопуляциях T. gesneriana, показатели жизненности ухудшались.

Ключевые слова: T. gesneriana L.; иенопопуляиия; структура морфологической изменчивости; виталитетная структура

Для цитирования. Лиджиева Н.Ц., Очирова А.С., Овадыкова Ж.В., Убушаева С.В. Структура морфологической изменчивости и виталитетная структура ценопопуляций Tulipa gesneriana L. на Ергенинской возвышенности // Siberian Journal of Life Sciences and Agriculture. 2021. T. 13, № 3. C. 261-275. DOI: 10.12731/2658-6649-2021-13-3-261-275

\title{
STRUCTURE OF MORPHOLOGICAL VARIABILITY AND VITALITY STRUCTURE OF CENOPOPULATIONS OF TULIPA GESNERIANA L. ON THE ERGENINSKAYA HILL
}

\author{
N.Ts. Lidzhieva, A.S. Ochirova, \\ Zh.V. Ovadykova, S.V. Ubushaeva
}

Background. The study of the vitality of individuals and the vital structure of populations is one of the most relevant approaches to assessing the state of rare plant species, which includes the object of research.

Purpose. The determination of the structure of morphological variability and vital structure of the coenopopulations of Tulipa gesneriana L. on the Ergeninsky Hill.

Materials and methods. The studies were carried out during two growing seasons in three coenopopulations from different plant communities. The level of variability of 12 morphological traits of plants was estimated according to S. A. Mamaev. Groups of system indicators were distinguished in the structure of variability. To assess the plasticity of a trait, the index of phytocenotic plasticity was used, and the vitalit spectrum of populations was used using the Yu. A. Zlobin's method, vitalit population structure - vitalit index, vitalit type $-Q$ criterion, degree of prosperity or depressiveness of coenopopulations $-I Q$ index.

Results. Most of the studied traits of T. gesneriana plants in the first year of the study had higher values than in the following year, while varying mainly at the average and elevated levels. In the following year, the degree of variation in the signs increased.

The structure of the variability of morphological indicators of T. gesneriana in the first year of the study was composed of groups of ecological-biological and biologi- 
cal system indicators, in the following year, along with these two groups, a group of ecological system indicators appeared. An assessment of the viability of T. gesneriana coenopopulations revealed that they belong to the «thriving» type. The degree of prosperity of the coenopopulations, estimated using IQ, varied over the years.

Conclusion. Thus, the coenopopulations of T. gesneriana belonged to the vital type «thriving». In the second year of the study in the coenopopulations of T. gesneriana, the vital signs deteriorated.

Keywords: Tulipa gesneriana L.; coenopopulation; structure of morphological variability; vital structure

For citation. Lidzhieva N.TS., Ochirova A.S., Ovadykova Zh.V., Ubushaeva S.V. The structure of morphological variability and vitality structure of coenopopulations of Tulipa gesneriana L. on the Ergeninskaya Hill. Siberian Journal of Life Sciences and Agriculture, 2021, vol. 13, no. 3, pp. 261-275. DOI: 10.12731/26586649-2021-13-3-261-275

Морфобиологическая неоднородность особей в популяциях имеет в своей основе различие по комплексу их биологических свойств и особенностей, неоднородность условий обитания в растительном сообществе. В тоже время внутривидовая дифференциация является существенным фактором обеспечения гомеостаза популяции, проблема поддержания которого особенно важна для редких видов.

В морфогенезе растений интегрирован уровень процессов метаболизма, в связи с чем морфологический статус вегетативных и генеративных органов позволяет характеризовать жизнеспособность особей [1]. Под виталитетом понимают жизненное состояние растительных индивидуумов, с опорой на морфометрические показатели, оценивающие рост и продуктивность растений $[1,14]$. Изучение жизненности индивидуумов и виталитетной структуры популяций является одним из актуальных подходов в оценке состояния редких видов растений. К их числу относится объект нашего исследования - луковичный поликарпик, эфемероид Tulipa gesneriana L. (Liliaceae), рекомендованный к охране во многих регионах [5, 7 и др.]. В Красной книге Российской Федерации [6] вид отнесен к видам, сокращающимся в численности. Это обусловливает возрастающий интерес к изучению особенностей биологии и популяционным характеристикам видов рода Tulipa $[8,10,11,12,15,18-20$ и др.].

Цель исследования: определение структуры морфологической изменчивости и виталитетной структуры ценопопуляций Tulipa gesneriana L. на Ергенинской возвышенности в пределах Республики Калмыкия. 


\section{Материал и методика}

Исследования проводили в вегетационные сезоны 2017-2018 гг. в трех ценопопуляциях из разных растительных сообществ, произрастающих на светло-каштановой почве, разной степени засоления. Ценопопуляция № 1 приурочена к луковичномятликово - типчаково - ковылково - лерхополынному (Artemisia lerchiana - Stipa lessingiana - Festuca valesiaca - Poa bulbosa) сообществу, ценопопуляция № 2 - разнотравно-ковылково-лерхополынное (Artemisia lerchiana - Stipa lessingiana - Mixteherbosa) сообществу, ценопопуляция № 3 - злаково-прутняково-лерхопролынному (Artemisia lerchiana - Kochia prostrata - Poaceta) сообществу.

В каждой ценопопуляции случайным образом отбирали не менее 30 особей среднегенеративного возрастного состояния [14]. У них осуществляли изменение двенадцати морфологических признаков вегетативных и генеративных органов, без уничтожения особей [3].

Для оценки уровня изменчивости использовали коэффициент вариации, считая при его значениях $<7 \%$ изменчивость признака очень низкой; 7- $12 \%$ низкой, 13-20\% - средней; 21-40\% - высокий, > 40\% - очень высокий [9].

В структуре морфологической изменчивости выделяли группы системных индикаторов, используя особенности общей и согласованной изменчивости [13]. Согласованную изменчивость параметров определяли путем расчета коэффициента детерминации, представляющего собой коэффициент корреляции, усредненный для каждого учитываемого показателя.

Пластичность признака оценивали сопоставлением средних значений признаков за два года исследований как частное амплитуды пластичности и коэффициента свободного развития, представляющее собой наибольшее значение признака в оптимальных условиях: $\mathrm{I}_{\mathrm{p}}=(\mathrm{A}+\mathrm{B}) / \mathrm{A}$, где $\mathrm{I}_{\mathrm{p}}-$ индекс фитоценотической пластичности, А - максимальное, В - минимальное среднее значение признака в годы наблюдений [2].

Жизненность индивидуумов $T$. gesneriana характеризовали индексом виталитета особи (IVI) [1]. Ключевые признаки для вычисления индекса виталитета особи устанавливали с помощью предварительно проведенного корреляционного анализа.

Виталитетный спектр популяций получали с помощью методики Ю.А. Злобина [1]. Для этого ранжированный по индексу виталитета ряд особей распределяли по трем классам: «а»-с высоким, и пределах границ доверительного интервала среднего арифметического $(\overline{\mathrm{x}} \pm \delta)$.

Виталитетную структуру популяции характеризовали с помощью индекса виталитета ценопопуляции (IVC) [3]. При этом полагая, что наиболь- 
шие значения индекса IVC отражают благоприятные условия реализации потенциала роста, а наименьшие - неблагоприятные [4].

Виталитетный тип ценопопуляций выявляли, применяя с помощью критерия Q: у процветающих ценопопуляций $\mathrm{Q}=1 / 2(\mathrm{a}+\mathrm{b})>\mathrm{c}, \mathrm{y}$ равновесных ценопопуляций $\mathrm{Q}=1 / 2(\mathrm{a}+\mathrm{b})=\mathrm{c}$, у депрессивных ценопопуляций $\mathrm{Q}=1 / 2(\mathrm{a}+\mathrm{b})<\mathrm{c}[1]$.

Степень процветания или депрессивности ценопопуляций характеризовали индексом $\mathrm{I}_{\mathrm{Q}}=(\mathrm{a}+\mathrm{b}) / 2 \mathrm{c}$ [16]. Значение данного индекса, равное единице, соответствует равновесному состоянию ценопопуляции. Чем больше значение $\mathrm{I}_{\mathrm{Q}}$ отклоняется от единицы, тем больше степень процветания и депрессии.

\section{Результаты}

В ценопопуляциях T. gesneriana на Ергенинской возвышенности высота растений достигала 81,9-132,7 мм длина первого междоузлия - 9,8 -22,6 мм, длина второго междоузлия - 12,7-25,2 мм, длина цветочной стрелки 34.6 - 90,0 мм, длина листочка околоцветника - 24,2 - 35,8 мм, ширина листочка околоцветника - 12,3 -18,9 мм, длина нижнего листа 69,3-105,3 мм, ширина нижнего листа - 17,6 - 21,7 мм, длина среднего листа 59,6-82,7 мм, ширина среднего листа - 9,8-13,6 мм, длина верхнего листа - 44,2-66,9 мм, ширина верхнего листа - 6,3 - 9,8 мм.

Полученные данные по изменчивости биометрических признаков в ценопопуляциях T. gesneriana в два года исследования были скоррелированы с погодными условиями в период активной вегетации растений (табл. 1).

Таблииа 1.

\begin{tabular}{|c|c|c|c|c|c|c|c|c|c|c|c|c|}
\hline \multirow{3}{*}{ 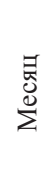 } & \multicolumn{2}{|c|}{2017 г. } & \multicolumn{2}{|c|}{2018 г. } & \multicolumn{2}{|c|}{2017 г. } & \multicolumn{2}{|c|}{2018 г. } & \multicolumn{2}{|c|}{2017 г. } & \multicolumn{2}{|c|}{2018 г. } \\
\hline & ర્ & 髱 & రิ & 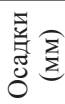 & Oृ & 氮 & ర్ర & 竘 & 0 & 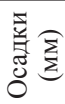 & ర్ర & 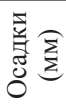 \\
\hline & \multicolumn{4}{|c|}{ Ценопопуляция № 1} & \multicolumn{4}{|c|}{ Ценопопуляция № 2} & \multicolumn{4}{|c|}{ Ценопопуляция № 3} \\
\hline 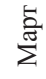 & 4,5 & 30,4 & $-2,8$ & 58,9 & 4,2 & 33,4 & $-1,6$ & 58,8 & 4,2 & 33,4 & $-1,6$ & 58,8 \\
\hline $\begin{array}{l}\text { 预 } \\
\text { 宗 }\end{array}$ & 10,8 & 53 & 10,5 & 11,2 & 9,4 & 38,1 & 10 & 3,2 & 10 & 38,1 & 10 & 3,2 \\
\hline
\end{tabular}

Морфологические признаки, определяемые ростовыми процессами организма, связаны с их приспособленностью к условиям обитания, уровню 
плотности, фитоценотической обстановке к $[16,17]$. Большинство признаков растений $T$. gesneriana в 2017 г. с большим объемом осадков и более высокими температурами марта-апреля имели большие значения, чем в 2018 году.

Соответственно в первый год исследования признаки варьировали преимущественно среднем и повышенном уровне. Очень высокий уровень изменчивости $\left(\mathrm{C}_{\mathrm{v}}=42,6 \%\right)$ выявлен у длины первого междоузлия, высокий уровень изменчивости $\left(\mathrm{C}_{\mathrm{v}}=33,2 \%\right)$ - у длины второго междоузлия (табл. 2).

В следующем году признаков, варьировавших на среднем уровне не отмечалось, оба междоузлия стали варьировать на очень высоком уровне, длина цветочной стрелки и ширина верхнего листа - на высоком, остальные восемь признаков - на повышенном уровне изменчивости.

\section{Изменчивость биоморфологических признаков (мм)}

Таблица 2. в ценопопуляциях Tulipa gesneriana в 2017 году

\begin{tabular}{|c|c|c|c|c|c|c|c|}
\hline \multirow{2}{*}{ Признаки } & \multirow{2}{*}{$\bar{x}$} & \multirow{2}{*}{$\mathrm{S}_{\overline{\mathrm{x}}}$} & \multirow{2}{*}{$\mathrm{C}_{\mathrm{v}}$} & \multirow{2}{*}{$\mathrm{S}_{\mathrm{cv}}$} & \multicolumn{2}{|c|}{ Пределы } & \multirow{2}{*}{$I_{p}$} \\
\hline & & & & & $\min$ & $\max$ & \\
\hline Высота растения & 112,2 & 2,78 & 25,94 & 1,75 & 42 & 191 & 0,19 \\
\hline Длина первого междоузлия & 18,6 & 0,76 & 42,58 & 2,87 & 0 & 34 & 0,34 \\
\hline Длина второго междоузлия & 21,8 & 0,69 & 33,24 & 2,24 & 4 & 49 & 0,12 \\
\hline Длина цветочной стрелки & 38,4 & 0,98 & 26,66 & 1,80 & 19 & 68 & 0,21 \\
\hline Длина листочка околоцветника & 33,2 & 0,48 & 14,82 & 1,00 & 20 & 46 & 0,13 \\
\hline Ширина листочка околоцветника & 18,5 & 0,34 & 19,30 & 1,30 & 6 & 32 & 0,04 \\
\hline Длина нижнего листа & 96,3 & 1,75 & 19,05 & 1,28 & 51 & 140 & 0,19 \\
\hline Ширина нижнего листа & 20,8 & 0,39 & 19,88 & 1,34 & 11 & 31 & 0,11 \\
\hline Длина среднего листа & 79,6 & 2,17 & 28,60 & 1,93 & 19 & 131 & 0,36 \\
\hline Ширина среднего листа & 13,1 & 0,29 & 22,97 & 1,55 & 6 & 21 & 0,12 \\
\hline Длина верхнего листа & 57,3 & 1,58 & 28,94 & 1,95 & 23 & 92 & 0,34 \\
\hline Ширина верхнего листа & 9,2 & 0,23 & 26,78 & 1,81 & 4 & 17 & 0,17 \\
\hline
\end{tabular}

В 2017 году наибольшую пластичность отмечали для трех признаков (Ip 0,34-0,36): длина первого междоузлия, длина среднего и верхнего листьев. В 2018 г. наряду с первым междоузлием высоко пластичными были высота растения, длина второго междоузлия и цветочной стрелки. Остальные признаки были менее пластичными. Наиболее константным показателем, обнаружившим минимальный уровень пластичности в 2017 г. была ширина листочка околоцветника $(\mathrm{Ip}=0,04)$, в 2018 г. - ширина нижнего листа (Ip=0,08) (табл. 2, 3). 
Изменчивость биоморфологических признаков (мм)

Таблица 3. в ценопопуляциях Tulipa gesneriana в 2018 году

\begin{tabular}{|c|c|c|c|c|c|c|c|}
\hline \multirow{2}{*}{ Признаки } & \multirow{2}{*}{$\bar{x}$} & \multirow{2}{*}{$\mathrm{S}_{\overline{\mathrm{x}}}$} & \multirow{2}{*}{$\mathrm{C}_{\mathrm{v}}$} & \multirow{2}{*}{$\mathrm{S}_{\mathrm{cv}}$} & \multicolumn{2}{|c|}{ Пределы } & \multirow{2}{*}{$\mathrm{I}_{\mathrm{p}}$} \\
\hline & & & & & $\min$ & $\max$ & \\
\hline Высота растения & 111,2 & 3,16 & 30,08 & 2,01 & 30 & 185 & 0,38 \\
\hline Длина первого междоузлия & 15,0 & 0,70 & 49,26 & 3,29 & 2 & 35 & 0,50 \\
\hline Длина второго междоузлия & 19,9 & 0,89 & 47,19 & 3,15 & 1 & 50 & 0,50 \\
\hline Длина цветочной стрелки & 48,8 & 2,43 & 39,18 & 2,62 & 14 & 75 & 0,40 \\
\hline Длина листочка околоцветника & 27,0 & 0,75 & 21,31 & 1,96 & 10 & 47 & 0,22 \\
\hline Ширина листочка околоцветника & 14,7 & 0,39 & 27,93 & 1,87 & 5 & 26 & 0,29 \\
\hline Длина нижнего листа & 80,7 & 1,9 & 24,96 & 1,67 & 27 & 146 & 0,26 \\
\hline Ширина нижнего листа & 18,6 & 0,38 & 21,50 & 1,44 & 10 & 30 & 0,09 \\
\hline Длина среднего листа & 74,0 & 1,82 & 25,98 & 1,74 & 30 & 135 & 0,19 \\
\hline Ширина среднего листа & 10,3 & 0,29 & 30,18 & 2,02 & 4 & 19 & 0,08 \\
\hline Длина верхнего листа & 52 & 1,23 & 24,96 & 1,67 & 25 & 105 & 0,23 \\
\hline Ширина верхнего листа & 6,9 & 0,23 & 35,94 & 2,4 & 2 & 17 & 0,16 \\
\hline
\end{tabular}

Структуру изменчивости морфологических показателей T. gesneriana в 2017 году слагали две группы системных индикаторов [13]. В группу эколого-биологических системных индикаторов (рис 1a, II) вошли длина первого и второго междоузлия, которые имели высокую общую и согласованную изменчивость.

Все остальные в это год исследования у T. gesneriana вошли в группу биологических системных индикаторов (рис. 1a, IV). В 2018 году, характеризовавшимся более неблагоприятными климатическими условиями в период роста и развития растений вида (табл. 1), наряду с данными двумя группами появилась группа экологических системных индикаторов, представленная «длиной цветочной стрелки» (рис. 16, I). Группа эколого-биологических системных индикаторов пополнилась шириной верхнего листа (рис. 1б, II). Промежуточными между эколого-биологических и биологических системных индикаторов оказались в этот год высота растения и ширина среднего листа. Остальные признаки продолжали оставаться в группе биологических системных индикаторов (рис. 1б, IV).

Признаков обладающих низкой общей и согласованной изменчивостью, относящихся к группе генетических системных индикаторов из числа исследованных признаков в оба года исследования не выявлено. 


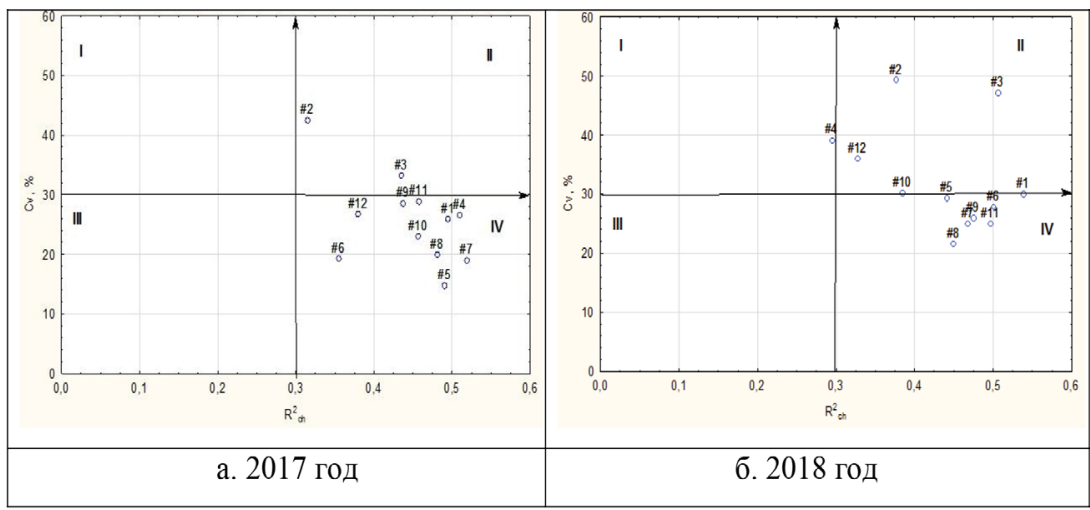

Рис. 1. Структура изменчивости морфологических показателей T. gesneriana: по оси абцисс $-\mathrm{R}_{\text {ch }}^{2}$ - согласованная изменчивость признаков, по оси ординат общая изменчивость (Cv), 1 - высота растения, 2 - длина междоузлия №1, 3 - длина междоузлия №2, 4 - длина цветочной стрелки, 5 - длина листочка околоцветника, 6 - ширина листочка околоцветника, 7 - длина нижнего листа, 8 - ширина нижнего листа, 9 - длина среднего листа, 10 - ширина среднего листа, 11 - длина верхнего листа, 12 - ширина верхнего листа

В процессе выявления ключевых признаков для вычисления индекса виталитета в ценопопуляциях $T$. gesneriana использовали результаты предварительно проведенного корреляционного анализа признаков особей. Анализ позволил выявить ключевые признаки: в 2017 году были высота растения, параметры цветка и нижнего листа; в 2018 году - высота растения, длина второго междоузлия, ширина листочка околоцветника, длины трех листов. Кэффициенты корреляии между ключевыми признаками составила $0,5-0,8(\mathrm{p}<0,05)$ в 2018 году число ключевых признаков возросло и сила связи между ними в большинстве пар сравнения была больше, чем в предыдущем году.

По результатам анализа ранжированного ряда индексов виталитета особей каждой исследованной ценопопуляции составлены виталитетные спектры (рис. 2).

Рассчитанные показатели жизненности и виталитетные типы ценопопуляций T. gesneriana приведены в таблице 4. В 2017 году в виталитетном спектре всех исследованных ценопопуляций преобладали особи среднего класса виталитета $(56,7-79,1 \%)$. Наиболее лучшее виталитетное состояние имела ценопопуляция №1 (IVC=1,097), наиболее плохое - ценопопуляция № 3 (IVC=0,914). 


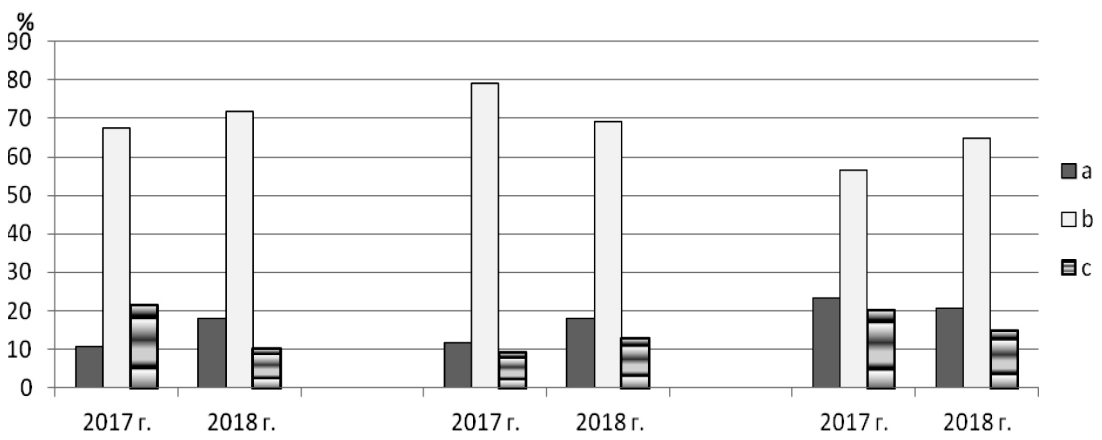

Ценопопуляция № 1 Ц Ценопопуляция № 2 Ценопопуляция № 3

Рис. 2. Виталитетные спектры ценопопуляций T. gesneriana

В 2018 году особи среднего класса виталитета продолжали преобладать в виталитетном спектре. В этом году ценопопуляция №3 имела лучшее жизненное состояние, но условия года максимально негативно отразились на ценопопуляции №2 (IVC=0,842). Оценка виталитета ценопопуляций T. gesneriana с использованием индекса IVC выявила, что его значения в 2018 году на $0,022-0,305$ больше, чем в 2017 году.

Таблица 4.

Показатели жизненности и виталитетный тип ценопопуляций

Tulipa gesneriana

\begin{tabular}{|c|c|c|c|c|c|c|c|c|}
\hline \multirow[t]{2}{*}{ Ценопопуляция } & \multirow[t]{2}{*}{ Год } & \multicolumn{3}{|c|}{$\begin{array}{c}\text { Частость } \\
\text { по классам } \\
\text { виталитета }\end{array}$} & \multirow[t]{2}{*}{ IVC } & \multirow[t]{2}{*}{ Q } & \multirow[t]{2}{*}{$\mathrm{I}_{\mathrm{Q}}$} & \multirow[t]{2}{*}{$\begin{array}{c}\text { Виталитетный } \\
\text { тип }\end{array}$} \\
\hline & & $\mathrm{a}$ & $\mathrm{b}$ & $\mathrm{c}$ & & & & \\
\hline \multirow{2}{*}{ № 1} & 2017 & 0,108 & 0,676 & 0,216 & 1,097 & 0,392 & 1,81 & процветающая \\
\hline & 2018 & 0,180 & 0,718 & 0,103 & 1,178 & 0,449 & 4,35 & процветающая \\
\hline \multirow{2}{*}{ №2 } & 2017 & 0,116 & 0,791 & 0,093 & 0,977 & 0,453 & 4,88 & процветающая \\
\hline & 2018 & 0,180 & 0,692 & 0,128 & 0,809 & 0,436 & 2,70 & процветающая \\
\hline \multirow{2}{*}{ №3 } & 2017 & 0,233 & 0,567 & 0,200 & 0,914 & 0,400 & 2,00 & процветающая \\
\hline & 2018 & 0,206 & 0,647 & 0,147 & 1,014 & 0,426 & 2,90 & процветающая \\
\hline
\end{tabular}

Оценка жизненности ценопопуляций T. gesneriana с использованием критерия Q выявил, что все исследованные ценопопуляции относятся к типу «процветающие». Степень процветания в разных ценопопуляциях, оцененная с помощью $\mathrm{I}_{\mathrm{Q}}$, колебалась по годам исследования. 


\section{Заключение}

У T. gesneriana наиболее высокопластичными с наибольшим ответом на изменение климатических условий года были признаки: высота растений, длина междоузлий, длина цветочной стрелки.

При последующей оценке влияния условий произрастания следует учитывать в первую очередь.

Исследованные ценопопуляции T. gesneriana весь период исследования относились к виталитетному типу «процветающие». В 2018 году, характеризовавшемся более низкими температурами и меньшим объемом осадков в период активной вегетации растений T. gesneriana, отмечали ухудшении показателей жизненности, выраженном индексом IVC.

\section{Список литературы}

1. Злобин Ю.А. Принципы и методы изучения ценотических популяций растений. Казань: издательство Казанского университета, 1989. 146 с.

2. Злобин Ю.А., Скляр В.Г., Клименко А.А. Популяции редких видов растений: теоретические основы и методика изучения. Сумы: Университетская книга, 2013. 439 c.

3. Ишбирдин А.Р., Ишмуратова М.М. К оценке виталитета ценопопуляций Rhodiola iremelica Boriss. по размерному спектру // Фундаментальные и прикладные проблемы популяционной биологии. Материалы VI Bсероссийского популяционного семинара. Ученые записки НТГСПА. 2004 С. 80-85.

4. Ишбирдин А.Р., Кливаденко Е.В. Ишмуратова М.М. Адаптивный морфогенез Solanum tuberosum // Известия Самарского научного центра Российской академии наук. 2011. T. 13, № 5(2). С. 76-78. http://www.ssc.smr.ru/media/ journals/izvestia/2011/2011_5_2_16.pdf

5. Красная книга Республики Калмыкия: в 2 т. Редкие и находящиеся под угрозой исчезновения растения и грибы / отв. ред. Н.М. Бакташева. Элиста: ЗАОр «НПП «Джангар», 2014. Т. 2. 199 с.

6. Красная книга Российской Федерации (растения и грибы) / сост. Р. В. Камелин и др. М.: Товарищество научных изданий КМК, 2008. 885 с.

7. Красная книга Ростовской области: в 2 т. Растения и грибы / науч. ред. В.В. Федяева. Ростов-на-Дону: Минприроды Ростовской области, 2014. Т. 2. 344 с.

8. Лыу Т.Н., Лиджиева Н.Ц., Лиджигоряева Ц.В. Зависимость изменчивости морфологических признаков растений от окраски околоцветника в ценопопуляции Tulipa gesneriana // Научная мысль Кавказа. 2015. № 4 (84). С. 119-123. https://doi.org/10.18522/2072-0181-2015-84-4-119-123 
9. Мамаев С.А. Формы внутривидовой изменчивости древесных растений. М.: Наука, 1972. 283 с.

10. Мухаметшина Л.В., Муллабаева Э.З., Ишмуратова М.М. Особенности биологии и ценопопуляционные характеристики видов рода Tulipa L. на Южном Урале // Вестник Удмуртского университета. Серия «Биология. Науки о Земле». 2015. №. 2. С. 101-108.

11. Очирова А.С., Зараева Б.М., Онкорова Н.Т., Лиджиева Н.Ц. Семенная продуктивность растений в ценопопуляциях видов рода Tulipa в условиях Республики Калмыкия // Известия Самарского научного центра Российской академии наук. 2018. Т. 20, № 5(4). C. 579-585. http://www.ssc.smr.ru/media/ journals/izvestia/2018/2018_5_579_585.pdf

12. Очирова А.С., Лыу Т.Н., Лиджиева Н.Ц. Изменчивость морфологических признаков растений и виталитетная структура ценопопуляций видов рода Tulipa (Liliaceae) в заповеднике «Черные земли» // Известия Самарского научного центра Российской академии наук. 2016. Т.18, № 5(2). С. 314-319. http://www.ssc.smr.ru/media/journals/izvestia/2016/2016_5_314_319.pdf

13. Ростова Н.С. Корреляции: структура и изменчивость. СПб.: Изд-во С.-Петербургского ун-та, 2002. 308 с.

14. Ценопопуляции растений (основные понятия и структура) / Отв. ред. А.А. Уранов, Т.И. Серебрякова. М.: Наука, 1976. 217 с.

15. Chernysheva O., Bukin Y., Krivenko D. The morphometric characters variability analysis of Tulipa uniflora (Liliaceae) in the Angara Region (Irkutsk Oblast, Russia) // BIO Web of Conferences. EDP Sciences, 2018, 21 August 2018, vol. 11. Article Number 00009. https://doi.org/10.1051/bioconf/20181100009

16. Grime J.P. Plant Strategies and Vegetation Processes, and Ecosystem Properties. 2nd edition. Chichester: John Wiley \& Sons Ltd, 2001, 417 p.

17. Harper J.L. Population Biology of Plants. London: Academic Press, 1977, 892 p.

18. Kashin A.S. et al. State of cenopopulations and morphological variability of Tulipa gesneriana (Liliaceae) in the northern Lower Volga region // Botanicheskiı̆ Zhurnal, 2016, vol. 101, no. 12, pp. 1430-1465. https://doi.org/10.1134/ S0006813616120061

19. Kashin A.S., Petrova N.A., Shilova I.V. Some features of the environmental strategy of Tulipa gesneriana L. (Liliaceae, Liliopsida) // Biology Bulletin, 2017, vol. 44, no. 10, pp. 1237-1245. https://doi.org/10.1134/S1062359017100053

20. Lidzhieva N.C., Lyu T.N., Onkorova N.T., Ochirova A.S., Ovadykova Zh.V. Edafichesky conditions of growth cenopopulation of types of the sort Tulipa in the reserve «The Black soil» // Atlantis Press. Atlantis Highlights in Material Sciences and Technology (AHMST). 2019, vol. 1, pp. 616-620. 


\section{References}

1. Zlobin Yu.A. Printsipy i metody izucheniya tsenoticheskikh populyatsiy rasteniy [Principles and methods of studying coenotic plant populations]. Kazan: Kazan University Press, 1989, 146 p.

2. Zlobin Yu.A., Sklyar V.G., Klimenko A.A. Populyatsii redkikh vidov rasteniy: teoreticheskie osnovy i metodika izucheniya [Populations of rare plant species: theoretical foundations and research methods]. Sumy: University book, 2013, 439 p.

3. Ishbirdin A.R., Ishmuratova M.M. K otsenke vitaliteta tsenopopulyatsiy Rhodiola iremelica Boriss. po razmernomu spektru [To assess the vitality of coenopopulations of Rhodiola iremelica Boriss. on the size spectrum]. Fundamental'nye i prikladnye problemy populyatsionnoy biologii. Materialy VI Vserossiyskogo populyatsionnogo seminara. Uchenye zapiski NTGSPA. [Fundamental and applied problems of population biology. Materials of the VI All-Russian Population Seminar. Scientific notes of NTGSPA], 2004, pp. 80-85.

4. Ishbirdin A.R., Klivadenko E.V. Ishmuratova M.M. Adaptivnyy morfogenez Solanum tuberosum [Adaptive morphogenesis of Solanum tuberosum]. Izvestiya Samarskogo nauchnogo tsentra Rossiyskoy akademii nauk [Izvestiya of the Samara Scientific Center of the Russian Academy of Sciences], 2011, vol. 13, no. 5(2), pp. 76-78. http://www.ssc.smr.ru/media/journals/izvestia/2011/2011_5_2_16.pdf

5. Krasnaya kniga Respubliki Kalmykiya: $v 2$ t. Redkie i nakhodyashchiesya pod ugrozoy ischeznoveniya rasteniya $i$ griby [The Red Book of the Republic of Kalmykia: in 2 vol. Rare and endangered plants and mushrooms]. Elista: ZAOr «SPE «Dzhangar», 2014. vol. 2. 199 p.

6. Krasnaya kniga Rossiyskoy Federatsii (rasteniya i griby)[ Red Book of the Russian Federation (plants and mushrooms)]. Moscow: KMK Scientific Partnership, 2008. 885 p.

7. Krasnaya kniga Rostovskoy oblasti: $v 2$ t. Rasteniya i griby [The Red Book of the Rostov region: in 2 tons. Plants and mushrooms]. Rostov-on-Don: Ministry of Natural Resources of the Rostov Region, 2014, vol. 2, 344 p.

8. Lyu T.N., Lidzhieva N.Ts., Lidzhigoryaeva Ts.V. Zavisimost' izmenchivosti morfologicheskikh priznakov rasteniy ot okraski okolotsvetnika $\mathrm{v}$ tsenopopulyatsii Tulipa gesneriana [Dependence of the variability of morphological characteristics of plants on the color of the perianth in the coenopopulation of Tulipa gesneriana]. Nauchnaya mysl' Kavkaza [Scientific thought of the Caucasus], 2015, no. 4 (84), pp. 119-123. https://doi.org/10.18522/2072-0181-2015-84-4-119-123

9. Mamaev S.A. Formy vnutrividovoy izmenchivosti drevesnykh rasteniy. Moscow: Science, 1972, $283 \mathrm{p}$.

10. Mukhametshina L.V., Mullabaeva E.Z., Ishmuratova M.M. Osobennosti biologii i tsenopopulyatsionnye kharakteristiki vidov roda Tulipa L. na Yuzhnom Urale 
[Features of biology and cenopopulation characteristics of species of the genus Tulipa L. in the southern Urals]. Vestnik Udmurtskogo universiteta. Seriya «Biologiya. Nauki o Zemle» [Bulletin of the Udmurt University. Series « Biology. earth science»], 2015, no. 2, pp. 101-108.

11. Ochirova A.S., Zaraeva B.M., Onkorova N.T., Lidzhieva N.Ts..Semennaya produktivnost' rasteniy $\mathrm{v}$ tsenopopulyatsiyakh vidov roda Tulipa $\mathrm{v}$ usloviyakh Respubliki Kalmykiya [Seed productivity of plants in coenopopulations of species of the genus Tulipa under the conditions of the Republic of Kalmykia]. Izvestiya Samarskogo nauchnogo tsentra Rossiyskoy akademii nauk.[Izvestiya of the Samara Scientific Center of the Russian Academy of Sciences], 2018, vol. 20, no. 5(4), pp. 579-585. http://www.ssc.smr.ru/media/journals/izvestia/2018/2018_5_579_585.pdf

12. Ochirova A.S., Lyu T.N., Lidzhieva N.Ts. Izmenchivost' morfologicheskikh priznakov rasteniy i vitalitetnaya struktura tsenopopulyatsiy vidov roda Tulipa (Liliaceae) v zapovednike «Chernye zemli» [The variability of morphological features in plants and vitality structure of cenopopulations of species of genus Tulipa (Liliaceae) in the natural reserve «The Black soil»]. Izvestiya Samarskogo nauchnogo tsentra Rossiyskoy akademii nauk [Izvestiya of the Samara Scientific Center of the Russian Academy of Sciences], 2016, vol. 1, no. 5 (2), pp. 314-319. http://www.ssc.smr.ru/media/journals/izvestia/2016/2016_5_314_319.pdf

13. Rostova N.S. Korrelyatsii: struktura i izmenchivost' [Correlations: structure and variability]. Saint-Petersburg: St. Petersburg University Publ., 2002, 308 p.

14. Tsenopopulyatsii rasteniy (osnovnye ponyatiya $i$ struktura) [Cenopopulation of plants (basic concepts and structure)]. M.: Science, 1976, 217 p.

15. Chernysheva O., Bukin Y., Krivenko D. The morphometric characters variability analysis of Tulipa uniflora (Liliaceae) in the Angara Region (Irkutsk Oblast, Russia). BIO Web of Conferences. EDP Sciences, 2018, 21 August 2018, vol. 11, Article Number 00009. https://doi.org/10.1051/bioconf/20181100009

16. Grime J.P. Plant Strategies and Vegetation Processes, and Ecosystem Properties. 2nd edition. Chichester: John Wiley \& Sons Ltd, 2001, 417 p.

17. Harper J.L. Population Biology of Plants. London: Academic Press, 1977, 892 p.

18. Kashin A.S. et al. State of cenopopulations and morphological variability of Tulipa gesneriana (Liliaceae) in the northern Lower Volga region. Botanicheskiŭ Zhurnal, 2016, vol. 101, no. 12, pp. 1430-1465. https://doi.org/10.1134/ S0006813616120061

19. Kashin A.S., Petrova N.A., Shilova I.V. Some features of the environmental strategy of Tulipa gesneriana L. (Liliaceae, Liliopsida). Biology Bulletin, 2017, vol. 44, no. 10, pp. 1237-1245. https://doi.org/10.1134/S1062359017100053 
20. Lidzhieva N.C., Lyu T.N., Onkorova N.T., Ochirova A.S., Ovadykova Zh.V. Edafichesky conditions of growth cenopopulation of types of the sort Tulipa in the reserve «The Black soil». Atlantis Press. Atlantis Highlights in Material Sciences and Technology (AHMST), 2019, vol. 1, pp. 616-620.

\section{ВКЛАД АВТОРОВ}

Лиджиева Н.Ц.: написание текста статьи, редактирование.

Очирова А.С.: получение данных, анализ полученных данных.

Овадыкова Ж.В.: обзор публикаций по теме статьи.

Убушаева С.В.: получение данных, анализ полученных данных.

\section{AUTHOR CONTRIBUTIONS}

Nina Ts. Lidzhieva: article editing.

Aleksandra S. Ochirova: obtaining data.

Zhanna V. Ovadykova: reviewing of publications of the article's theme.

Saglara V. Ubushaeva: obtaining data, analysis.

\section{ДАННЫЕ ОБ АВТОРАХ}

Лиджиева Нина Цереновна, д.б.н., профессор кафедры общей биологии и физиологии

Федеральное государственное бюджетное общеобразовательное учреждение выстего образования «Калмыцкий государственный университет имени Б.Б. Городовикова»

ул. Пушкина, 11, г. Элиста, 358009, Российская Федерация for-lidjieva@yandex.ru

\section{Очирова Александра Сергеевна, аспирант}

Федеральное государственное бюджетное общеобразовательное учреждение высшего образования «Калмыцкий государственный университет имени Б.Б. Городовикова»

ул. Пушкина, 11, г. Элиста, 358009, Российская Федерация ochirowa.alex@yandex.ru

Овадыкова Жанна Васильевна, кандидат сельскохозяйственных наук, доцент кафедры агрономии Федеральное государственное бюджетное общеобразовательное учреждение высшего образования «Калмыцкий государственный университет имени Б.Б. Городовикова» 
ул. Пушкина, 11, г. Элиста, 358009, Российская Федерация zhanna_ovadykova@mail.ru

Убушаева Саглара Владимировна, кандидат сельскохозяйственных наук, доцент кафедры агрономии Федеральное государственное бюджетное общеобразовательное учреждение выстего образования «Калмыикий государственный университет имени Б.Б. Городовикова»

ул. Пушкина, 11, г. Элиста, 358009, Российская Федеращия saglara-u@mail.ru

\section{DATA ABOUT THE AUTHORS}

Nina Ts. Lidzhieva, Doctor of Biology, Professor Department of General Biology and Physiology

Kalmyk State University named after B.B. Gorodovikova

11, Pushkin Str., Elista, 358009, Russian Federation

for-lidjieva@yandex.ru

SPIN-code: 3661-2682

ORCID: 0000-0003-2668-698X

Aleksandra S. Ochirova, Postgraduate Student

Kalmyk State University named after B.B. Gorodovikova

11, Pushkin Str., Elista, 358009, Russian Federation

ochirowa.alex@yandex.ru

ORCID: 0000-0001-9924-3368

Zhanna V. Ovadykova, Candidate of Agriculture, Associate Professor of the Department of Agronomy

Kalmyk State University named after B.B. Gorodovikova

11, Pushkin Str., Elista, 358009, Russian Federation

zhanna_ovadykova@mail.ru

SPIN-code: 8079-8320

ORCID: 0000-0001-7539-6909

Saglara V. Ubushaeva, Candidate of Agriculture, Associate Professor of the Department of Agronomy

Kalmyk State University named after B.B. Gorodovikova

11, Pushkin Str., Elista, 358009, Russian Federation saglara-u@mail.ru 